\title{
Waterpipe Smoking and Dependence are Associated with Chronic Obstructive Pulmonary Disease: A Case-Control Study
}

\author{
P. Salameh ${ }^{*}, 1$ M. Waked ${ }^{2}$, G. Khayat ${ }^{3}$ and M. Dramaix ${ }^{4}$ \\ ${ }^{1}$ Lebanese University - Faculties of Pharmacy \& of Public Health, Beirut, Lebanon \\ ${ }^{2}$ Saint George Hospital - Beirut \& Balamand University - Faculty of Medicine, Beirut, Lebanon \\ ${ }^{3}$ Hôtel Dieu de France Hospital - Beirut \& Saint Joseph University- Faculty of Medicine, Beirut, Lebanon \\ ${ }^{4}$ Université Libre de Bruxelles, School of Public Health, Brussels, Belgium
}

\begin{abstract}
Introduction: Waterpipe smoking gained popularity during recent years. Although waterpipe smoking exposes people to the same noxious substances found in cigarettes, popular belief considers it harmless. Our objective was to evaluate the association between waterpipe smoking and dependence, and COPD.

Methods: We conducted a case-control study in two tertiary care hospitals. Cases were included if diagnosed as COPD by a pulmonologist and confirmed by post-bronchodilator $\mathrm{FEV} 1 / \mathrm{FVC}<0.7$; controls were included if free of any respiratory disease or symptom. After oral consent, a standardized questionnaire was administered and spirometry results were collected.

Results: 211 COPD cases and 527 controls were studied. In previous smokers, any smoking type was associated with COPD. The ORs were 29.0[14.3-58.8] $(\mathrm{p}<0.001)$ for previous cigarette smoking, 11.7[4.4-31.2] $(\mathrm{p}<0.001)$ for previous waterpipe smoking, and 44.1[16.3-4.4] $(\mathrm{p}<0.001)$ for previous mixed smoking. In current smokers, the ORs were 20.5[10.2-41.2] $(\mathrm{p}<0.001)$ for cigarette smoking, 1.8[0.5-5.9] $(\mathrm{p}=0.299)$ for waterpipe smoking, and 9.4[3.81-23.0] $(p<0.001)$ for mixed smoking. Nevertheless, we found in waterpipe current smokers, an $O R=8.9[3.9-20.7]$ ( $p<0.001)$ for the association between dependence evaluated by LWDS-11 scale, and COPD. These results were confirmed by stratified and multivariate analysis, after adjustment for cigarette smoking and confounding variables. A cumulative smoking of one waterpipe per week for 20years (or its equivalent) was predictive of higher risk of COPD.
\end{abstract}

Discussion: Whereas evidence showing harmful effects of waterpipe smoking is sparse, this study showed a high OR between the risk of developing COPD and being an ex-smoker of waterpipe, or a current waterpipe dependent individual. Additional studies are necessary to confirm our results.

Keywords: Waterpipe, dependence, COPD, case-control, clinical.

\section{INTRODUCTION}

Waterpipe (WP) smoking is quickly spreading in Middle Eastern countries and the world $[1,2]$. Details can be found in several references [3-6]. Because the produced smoke passes through water in the device, many smokers think that it is less harmful than cigarette smoking. Nevertheless, WP smokers are potentially exposed to the cigarettes substances that are harmful, and although studies concerning WP smoking effects are not extensive, they suggest that it leads to cancer, genetic damage, lung diseases and other conditions in active and passive smokers [7-12]. It is now considered a global public health threat by the World Health Organization [3], and given the large number of WP smokers, it is essential to study the health effects of waterpipe smoking with renewed emphasis [13]. In a crosssectional study, we had found prevalence ratios of 2.5 for

*Address correspondence to this author at the Jdeidet El Meten, Chalet Suisse Street, Ramza Azzam bldg, 5th Floor, ZIP Code: 00961, Beirut, Lebanon; Tel: 009613385542; Fax: 009611696600; E-mails: psalameh@ul.edu.lb, pascalesalameh1@hotmail.com physician diagnosed respiratory diseases and chronic bronchitis symptoms in waterpipe smokers versus never smokers [14].

Since waterpipe smoking is a habit with physiological, psychological and social dimensions [15], it may manifest in several patterns. Around $80 \%$ of waterpipe smokers are not dependent on it [14] and may thus smoke irregularly. So, we would consider waterpipe smoking and waterpipe dependence as interesting exposure variables, to be linked with chronic obstructive pulmonary disease (COPD).

The primary objective of this study is thus to evaluate the association between WP smoking, WP dependence and COPD.

\section{METHODS}

\section{Study Design}

It is a multicenter case-control study, performed in two tertiary care hospitals in Beirut, comparing a group of patients having COPD with a control group. WP exposure, WP dependence and socio-demographic characteristics were 
compared in both groups. Since the study was observational and there was no traceability of patients, the Internal Review Board (IRB) waived the need for an official approval to perform the study, provided the study respected patients' autonomy and confidentiality.

\section{Study Population}

The whole study population was composed of nonhospitalized individuals. The COPD group was composed of consecutive newly diagnosed outpatient cases of mild, moderate or severe COPD. Cases were included if they were $\geq 40$ years of age, free of any other respiratory disease, diagnosed as COPD by a chest physician, and had a postbronchodilator FEV1/FVC $<0.7$.

Consecutive outpatients consulting for various extrapulmonary problems were included as controls if they were $\geq$ 40 years of age, free of COPD or any other respiratory disease (no asthma, no lung cancer, no lung fibrosis...), and not complaining of any chronic respiratory symptom (no chronic cough, no chronic sputum production, no wheezing, no dyspnea at rest or on exertion); no other exclusion criterion was applied. They were taken from all outpatient clinics situated close to the respiratory clinic: patients attending clinics of cardiology, endocrinology, dermatology, nephrology, hematology, urology, gastroenterology, gynecology, ophthalmology, pre-surgery consultation, and Ear, Nose and Throat were approached. Moreover, people accompanying cases (family members or friends) could also be taken as controls. For validation purposes, a random sample of 30 control individuals was tested with postbronchodilator spirometry, to ensure the absence of COPD.

\section{Data Collection}

COPD patients were evaluated for dyspnea, chronic cough and expectorations. They were classified by spirometry according to GOLD guidelines [16]. After an informed consent, a standardized questionnaire evaluated age, gender, height, weight, education, work status, marital status, detailed cigarette and waterpipe smoking history (current, previous or never smokers), passive smoking, declared exposure to smokes and fumes at work and home, polluted areas residency history and consumption of fruits and vegetables.

Education was divided into five classes of illiterate, primary, complementary, secondary and academic education levels. Work status was categorized into currently working, retired, not finding a job, and never working, while marital status was categorized into married, single and widow/divorced.

Cigarette smoking was defined as smoking more than 1 pack in a lifetime, while current waterpipe smoking was defined as a positive answer to the question "do you regularly smoke waterpipe" and previous waterpipe smoking as a positive answer to the question "were you a regular smoker of waterpipe". Frequency and duration of smoking were recorded for both cigarette and waterpipe. Cumulative smoking doses were subsequently calculated, as frequency multiplied by mean quantity: for cigarettes, it was the number of packs per day multiplied by the duration of smoking in years (packs*years); likewise, for waterpipe, it was the mean number of waterpipes smoked per week multiplied by the duration of smoking in years (waterpipes*years).

Passive smoking was addressed by questions about the number of smokers at home and at work, and the mean number of hours of exposure to their smoke. For exposure to smokes at home, questions about heating and cooking were asked as independent variables: the uses of diesel, wood, hot air, butane gas, electricity, central heating were addressed. Polluted areas were assessed using the following items: living close $(<100 \mathrm{~m})$ to a busy and heavy traffic road, and living close $(<100 \mathrm{~m})$ to a local power plant (which is a diesel exhaust source). Frequency of consumption of fruits and vegetables was also evaluated.

Cigarette and waterpipe dependence scores according to well known Fagerström Test for Nicotine Dependence (FTND) [17] and LWDS-11 [15], respectively. LWDS has already been developed and validated in the Lebanese population: it is composed of four subscales, the first representing nicotine dependence, the second negative reinforcement, the third psychological craving, and the fourth reflecting positive reinforcement. It has adequate internal consistency and test-retest reproducibility. Results were biologically and psychologically sound. It is a useful clinical and epidemiological tool. LWDS-11 score $\geq 10$ defines WP dependence [15].

\section{Sample Calculation}

Sample size calculation was performed with an alpha risk of $5 \%$ and a beta risk of $20 \%$. The mean percentage of Lebanese who smoke and could theoretically be exposed to WP is around 50\% [18] and $20 \%$ of these are dependent to waterpipe; [14] thus, $10 \%$ of the general population is considered WP dependent. To show a twofold increase in risk of COPD due to WP dependence, we needed a sample of 721 subjects: 515 controls for 206 cases.

\section{Statistical Analysis}

Independent laypersons entered the data. SPSS software, version 13.0 was used. Quality control of data entry and data cleaning were carried out by researchers. A p-value $\leq 0.05$ was considered significant. Missing data were not replaced since they were fewer than $10 \%$ of values. For continuous variables used in comparison of groups, we used ANOVA or students' tests for variables with adequate normal distribution. For non-normally distributed continuous variables and for non-continuous quantitative and ordinal variables, the Kruskal-Wallis test was used. For categorical variables, the Chi2 and Fisher exact tests were used when applicable.

The major dependent variable was: being diagnosed with COPD or not, based on post bronchodilator FEV1/FVC values. Independent variables were waterpipe smoking and dependence score. Cumulative WP exposure was expressed in WP-years (Number of WP smoked per week $\mathrm{x}$ the duration of WP smoking in years = number of WP-years). Dose-effect relationships were evaluated with trend tests and served to determine a cut-off point of cumulative waterpipe exposure. A stratified analysis was carried out over cigarette smoking, and multivariate results were presented for cigarette and non cigarette smokers. 
Multivariate analysis compared measures between groups of comparison, taking into account potential confounding variables of a p-value $<0.20$ in bivariate analysis: ever cigarette smoking, gender, residency, age, height, weight, body mass index, education, work status, marital status and number of smokers to which a person was potentially exposed (passive smoking at home and work), in addition to factors that affect COPD (even living close to a busy road, living close to a diesel exhaust source, heating home or cooking on diesel or solid fuels, and eating low quantities of fruits and vegetables). Logistic regressions were chosen because of the dichotomous dependent variable (COPD), while three major independent variables were evaluated: current waterpipe smoking, waterpipe dependence and previous waterpipe smoking (in separate models). Moreover, a first order interaction term was introduced, respectively (waterpipe smoking*ever smoking cigarette), (waterpipe dependence*ever smoking cigarette) OR (previous waterpipe smoking*ever smoking cigarette). Stepwise descendant likelihood ratio logistic regressions were applied on the global population, on cigarette smokers and non cigarette smokers. The final models were retained. Point estimates, 95\% confidence intervals and p-values were presented.

\section{RESULTS}

\section{Description of the Population}

Five hundred and seventy persons with chronic respiratory symptoms were approached in total; among them, 549 agreed to participate $(96.3 \%)$. Non participants gave the following reasons for their non participation: no time $(70 \%)$ and no particular reason (30\%). Post bronchodilation spirometry was performed for all 549 patients (100\%). After bronchodilation, 211 patients $(38.4 \%)$ fulfilled the definition of COPD (post-bronchodilator FEV1/FVC $<0.70$ ), while the rest, i.e. $338(61.6 \%)$ persons with respiratory symptoms, did not fulfill this definition, and thus could not be classified; they were subsequently removed from the analysis.

Thus, for the 211 COPD cases, the mean postbronchodilator FEV1/FVC for COPD patients was 0.60 $(\mathrm{SD}=0.08)$ : they were classified as follows: there were $38(17.9 \%)$ stage I, $121(57.6 \%)$ stage II, $45(21.2 \%)$ stage III, and $7(3.3 \%)$ stage IV COPD severity class.

For controls, 650 persons were approached; 71 were subsequently excluded because they declared suffering from miscellaneous respiratory symptoms. Moreover, 52 refused to participate to the study, for reasons similar to those stated above. Eventually, 527 were included as controls. A random sample of 30 control individuals were performed postbronchodilator spirometry; they all had a FEV1/FVC of more than 0.7 (mean=0.85; $\mathrm{SD}=7.50)$; thus they were all free from COPD. Among 527 controls, 323 (63.2\%) declared themselves totally healthy with no chronic diseases: they were all accompanying cases, family members or friends. The rest of controls [204/527(38.7\%)] were individuals consulting for non respiratory patients, classified as follows: $42(8 \%)$ for cardiology problems, $15(2.9 \%)$ for endocrinology, $19(3.6 \%)$ for dermatology, $9(1.7 \%)$ for hematology/oncology, $8(1.5 \%)$ for nephrology, $9(1.7 \%)$ for urology, $19(3.6 \%)$ for gastroenterology, $8(1.5 \%)$ for gynecology, 17(3.2\%) for ophthalmology, 3(0.6\%) for Ear Nose and Throat problems and $15(2.9 \%)$ for pre-surgery consultation. Forty patients $(7.6 \%)$ did not declare the reason for their medical consultation.

\section{Baseline Characteristics}

Significant differences exist between cases and controls (Table 1). Cases were older $(\mathrm{p}<0.001)$, more often males $(p=0.004)$, less educated $(p<0.001)$, retired or never working $(\mathrm{p}<0.001)$, and widows or divorced $(\mathrm{p}<0.001)$.

Table 1. Baseline Characteristics of Cases and Controls

\begin{tabular}{|c|c|c|c|}
\hline Characteristic & $\begin{array}{c}\text { Controls* } \\
\text { N=527 } \\
\%\end{array}$ & $\begin{array}{c}\text { Cases* } \\
\mathrm{N}=211 \\
\%\end{array}$ & P-value \\
\hline Age & & & \multirow{7}{*}{$<0.001$} \\
\hline 40-44 years & $190(36.1 \%)$ & $4(1.9 \%)$ & \\
\hline $45-49$ years & $139(26.4 \%)$ & $10(4.7 \%)$ & \\
\hline $50-54$ years & $70(13.3 \%)$ & $21(10.0 \%)$ & \\
\hline $55-59$ years & $42(8.0 \%)$ & $30(14.2 \%)$ & \\
\hline $60-64$ years & $33(6.3 \%)$ & $29(13.7 \%)$ & \\
\hline 65 years + & $53(10.1 \%)$ & $117(55.5 \%)$ & \\
\hline Gender & & & \multirow{3}{*}{0.004} \\
\hline Males & $233(44.3 \%)$ & $118(55.9 \%)$ & \\
\hline Females & $293(55.7 \%)$ & $93(44.1 \%)$ & \\
\hline Education & & & \multirow{6}{*}{$<0.001$} \\
\hline Never been to school & $6(1.1 \%)$ & $9(4.3 \%)$ & \\
\hline Primary or less & $39(7.4 \%)$ & $51(24.3 \%)$ & \\
\hline Complementary or less & $64(12.2 \%)$ & $52(24.8 \%)$ & \\
\hline Secondary or less & $170(32.4 \%)$ & $67(31.9 \%)$ & \\
\hline University degree & $246(46.9 \%)$ & $31(14.8 \%)$ & \\
\hline Working status & & & \multirow{5}{*}{$<0.001$} \\
\hline Currently working & $354(67.2 \%)$ & $65(30.8 \%)$ & \\
\hline Retired & $47(8.9 \%)$ & $62(29.4 \%)$ & \\
\hline Not finding a job & $5(0.9 \%)$ & $1(0.5 \%)$ & \\
\hline Does never work & $121(23.0 \%)$ & $83(39.3 \%)$ & \\
\hline Marital status & & & \multirow{4}{*}{$<0.001$} \\
\hline Married & $437(83.6 \%)$ & $175(83.7 \%)$ & \\
\hline Single & $70(13.4 \%)$ & $13(6.2 \%)$ & \\
\hline Widow or divorced & $16(3.1 \%)$ & $21(10.0 \%)$ & \\
\hline
\end{tabular}

*Numbers may sum inferior to the total (100\%) due to missing values.

\section{Smoking History Details}

Compared to never smoking, all types of smoking were associated with a higher risk of COPD (Table 2). Among exsmokers, mixed smokers (cigarettes \& waterpipe) had the highest association with COPD $(\mathrm{OR}=44.1)$, followed by cigarette smokers $(\mathrm{OR}=28.99)$, and waterpipe smokers $(\mathrm{OR}=11.67)$.

Among current smokers, cigarette smokers have the highest association $(\mathrm{OR}=20.5)$, followed by mixed smokers $(\mathrm{OR}=9.37)$ and waterpipe smokers $(\mathrm{OR}=1.78)$. However, when looking at dependence, mixed waterpipe and cigarette dependence showed the highest association with COPD 
Table 2. Active and Passive Smoking History in Cases and Controls

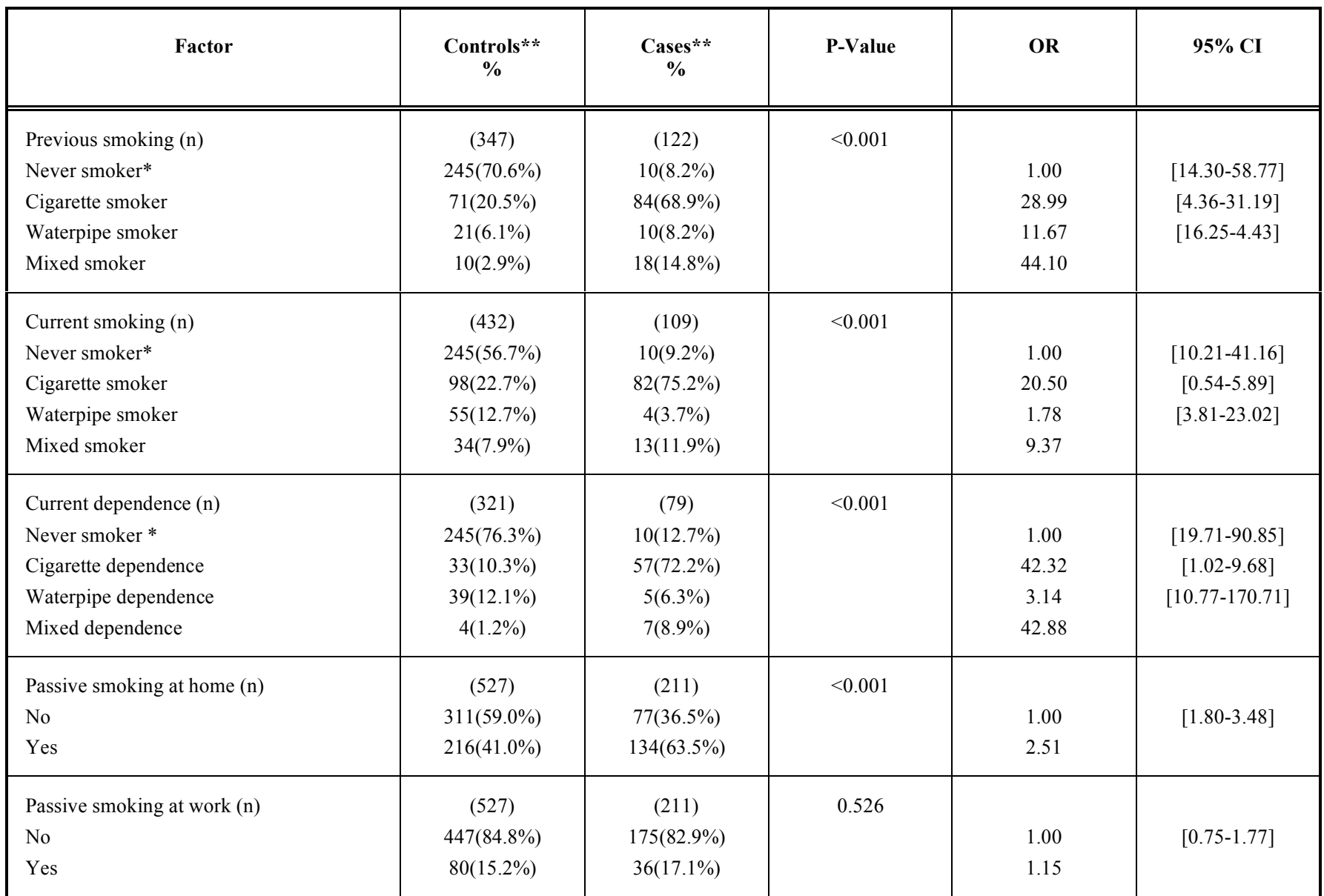

${ }^{*}$ Never smokers are the same in all comparisons; they are considered the reference control group for all comparisons; $* *$ Numbers may sum inferior to the total (100\%) due to missing values.

$(\mathrm{OR}=42.88)$, followed by cigarette dependence $(\mathrm{OR}=42.32)$ and waterpipe dependence $(\mathrm{OR}=3.14)$. Moreover, being exposed to passive smoking at home increases the risk of COPD $(\mathrm{OR}=2.51 ; \mathrm{p}<0.001)$.

When comparing waterpipe dependent current smokers with never smokers and waterpipe non dependent smokers, an OR of 8.93 [3.85-20.68] was found $(\mathrm{p}<0.001)$; in this case, when stratifying for cigarette smoking, no qualitative interaction was found (tests of homogeneity of the Odds Ratio between strata ( $\mathrm{p}$-value $=0.083$ ); in non cigarette smokers stratum, $\mathrm{OR}=1.91$ and in cigarette smokers stratum, $\mathrm{OR}=16.25)$. A quantitative interaction was suspected since ORs between strata are highly heterogeneous. The other way round, cases had a mean LWDS-11=18.44, while controls had $11.59(\mathrm{p}<0.001)$.

Moreover, when comparing previous waterpipe smokers versus never smokers, an $\mathrm{OR}=22.13[9.82-49.89]$ was found $(\mathrm{p}<0.001)$. Similar results were found for stratified analysis, and a quantitative interaction was also suspected. Fig. (1) presents the relationship of COPD with waterpipe smoking and dependence.

\section{Dose-Effect Relationships}

Significant dose-effect relationships were found for all kinds of smoking: higher cumulative doses of previous cigarette, current cigarette, previous waterpipe frequency and duration, and current waterpipe frequency and duration are associated with increased risk of COPD ( $<0.001$ for all). Current low doses of waterpipe have no association with COPD; high cumulative doses have a strong to unlimited one (Table 3). A cut-off point of 20 waterpipe-years for current and previous smoking was chosen for further analysis.

Fig. (2) shows waterpipe dependence dose-effect relationship, with never smokers as the reference category. The higher the dependence score on LWDS-11, the higher the risk of COPD: for non dependent waterpipe smokers (LWDS-11=1-9), OR=0; for moderate dependent (LWDS$11=10-16$ ), $\mathrm{OR}=5.56$, and for highly dependent (LWDS$11>16), \mathrm{OR}=12.24(\mathrm{p}<0.001$ for trend $)$.

\section{Multivariate Analysis}

A step-wise descendent logistic regression was run, taking smoking of 20 waterpipe-years or more as a major independent variable $(n=734 ; 210$ COPD cases and 524 controls), the retained model adequately fitted the data: $\mathrm{R}^{2}$ of Nagelkerke $=0.613$ and Hosmer Lemeshow test p-value was 0.438 ; moreover, $85.8 \%$ of individuals were adequately classified by the model. Again, we found no interaction between waterpipe and cigarette smoking (the interaction term was removed from the model). There was however a significant positive association between ever waterpipe smoking and COPD $(\mathrm{ORa}=2.43[1.18-4.97] ; \mathrm{p}=0.015)$. Older 


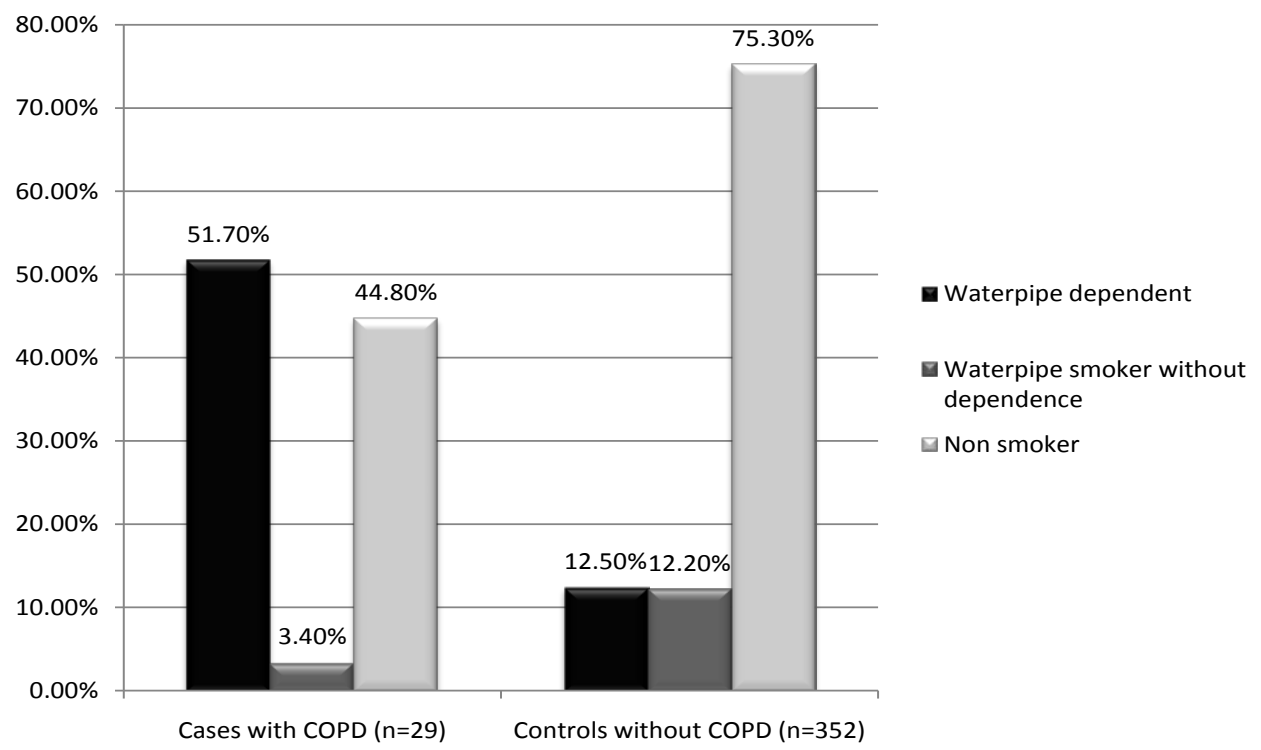

Fig. (1). Current waterpipe smoking, dependence and COPD. Cases of Chronic Obstructive Pulmonary Disease (COPD) are compared with controls $(\mathrm{p}<0.001)$.

age $(\mathrm{ORa}=1.94[1.68-2.25] ; \mathrm{p}<0.001)$, ever smoking cigarette $(\mathrm{ORa}=18.47[9.61-35.49] ; \mathrm{p}<0.001)$, lower education $(\mathrm{ORa}=1.46[1.15-1.84] ; \mathrm{p}=0.001)$, ever living close to a busy road $(\mathrm{ORa}=1.72[1.07-2.77] ; \mathrm{p}=0.026)$, heating house by hot air $(\mathrm{ORa}=2.51[1.17-5.36] ; \mathrm{p}=0.018)$ and not electrically $(\mathrm{ORa}=1.71[1.06-2.75] ; \mathrm{p}=0.027)$ were also associated with COPD (Table 4).

\section{Subgroups Multivariate Analyses}

In Table 4, we also present multivariate analyses for the association between COPD and waterpipe smoking in subgroups. Cigarette smokers subgroup: when taking smoking 20 waterpipe-years or more as a major independent variable ( $n=406 ; 196$ COPD cases and 210 controls), the retained model adequately fitted the data: $\mathrm{R}^{2}$ of Nagelkerke $=0.476$ and Hosmer Lemeshow test pvalue $=0.124$; moreover, $79.3 \%$ of individuals were adequately classified by the model. There was no significant relationship between waterpipe smoking and COPD $(\mathrm{ORa}=1.78[0.79-4.03] ; \mathrm{p}=0.164)$. Never cigarette smokers subgroup: when taking smoking of 20 waterpipe-years or more as a major independent variable $(n=328 ; 14$ COPD cases and 314 controls), the retained model adequately fitted the data: $\mathrm{R}^{2}$ of Nagelkerke $=0.554$ and Hosmer Lemeshow test $\mathrm{p}$-value $=0.773$; moreover, $97.3 \%$ of individuals were adequately classified by the model. There was a significant, positive and unlimited relationship between waterpipe smoking and COPD $(\mathrm{ORa}=11.65[1.76-77.08] ; \mathrm{p}=0.011)$.

All waterpipe smokers subgroup: When taking smoking of more than 20 waterpipe-years as the major independent variable ( $n=416 ; 55$ COPD cases and 361 controls), the retained model generated by the stepwise descendant logistic regression adequately fitted the data: $\mathrm{R}^{2}$ of Nagelkerke $=0.723$ and Hosmer Lemeshow test pvalue $=0.923$. Moreover, $95.2 \%$ of individuals were adequately classified by the final model. There was a positive strong association between previous waterpipe smoking and COPD (ORa=3.91[1.25-12.19]; $\mathrm{p}=0.019)$.
Current waterpipe smokers subgroup: When taking current smoking of more than 20 waterpipe-years as the major independent variable $(n=358 ; 27$ COPD cases and 331 controls), the retained model generated by the descendant stepwise logistic regression adequately fitted the data: $\mathrm{R}^{2}$ of Nagelkerke $=0.656$ and Hosmer Lemeshow test pvalue $=0.893$. Moreover, $96.4 \%$ of individuals were adequately classified by the final model. There was however a significant positive and unlimited association between current waterpipe smoking and COPD (ORa=13.24[2.2179.20]; $\mathrm{p}=0.005)$.

When taking waterpipe dependence as the major independent variable $(n=355 ; 26$ COPD cases and 329 controls), the retained model generated by the descendant step-wise logistic regression adequately fitted the data: $\mathrm{R}^{2}$ of Nagelkerke $=0.625$ and Hosmer Lemeshow test pvalue $=0.863$. Moreover, $95.5 \%$ of individuals were adequately classified by the final model. There was a significant positive and strong association between current waterpipe dependence and COPD $(\mathrm{ORa}=5.88[1.11-$ 31.05]; $\mathrm{p}=0.037)$.

\section{DISCUSSION}

This is the first study that thoroughly looks at the relationship between waterpipe smoking and COPD. In previous smokers, we found a high OR between the risk of developing COPD and being an ex-smoker of waterpipe. In current smokers waterpipe smoking seems harmless at first sight $(\mathrm{OR}=1.78[0.54-5.89])$ : the reverse causality concept may be applied here for new waterpipe smoker, this habit being a relatively new trend in Lebanon. However, the risk of COPD was found high with waterpipe dependence and with cumulative smoking $\geq 20$ waterpipe-years versus non smokers. These results were confirmed by dose-effect relationships (in terms of frequency, duration and cumulative exposure) and by multivariate analyses.

In previous cigarette, WP and mixed smokers, we found higher ORs with the risk of developing COPD than in current 
Table 3. Smoking Dose-Effect Relationship

\begin{tabular}{|c|c|c|c|c|c|}
\hline Dose & $\begin{array}{c}\text { Controls* } \\
\%\end{array}$ & $\begin{array}{c}\text { Cases* } \\
\%\end{array}$ & P-Value & OR & $95 \% \mathrm{CI}$ \\
\hline $\begin{array}{c}\text { Previous cigarette (cumulative/day) (n) } \\
<1 \text { pack-year } \\
1-18 \text { pack-years } \\
18.1-56 \text { pack-years } \\
>56 \text { pack-years }\end{array}$ & $\begin{array}{c}(324) \\
247(76.2 \%) \\
40(12.3 \%) \\
29(9.0 \%) \\
8(2.5 \%)\end{array}$ & $\begin{array}{c}(112) \\
10(8.9 \%) \\
6(5.4 \%) \\
36(32.1 \%) \\
60(53.6 \%)\end{array}$ & $<0.001$ & $\begin{array}{c}1.00 \\
3.71 \\
30.66 \\
185.25\end{array}$ & $\begin{array}{c}{[1.28-10.76]} \\
{[13.79-68.19]} \\
{[70.12-489.44]}\end{array}$ \\
\hline $\begin{array}{l}\text { Previous waterpipe (cumulative/week) }(\mathrm{n}) \\
<0.1 \text { waterpipe-year } \\
0.1-29.9 \text { waterpipe-years } \\
>=30 \text { waterpipe-years }\end{array}$ & $\begin{array}{c}(273) \\
246(90.1 \%) \\
15(5.5 \%) \\
12(4.4 \%)\end{array}$ & $\begin{array}{c}(38) \\
10(26.3 \%) \\
6(15.8 \%) \\
22(57.9 \%)\end{array}$ & $<0.001$ & $\begin{array}{c}1.00 \\
9.84 \\
45.10\end{array}$ & $\begin{array}{c}{[3.15-30.72]} \\
{[17.52-116.12]}\end{array}$ \\
\hline $\begin{array}{c}\text { Current cigarette (cumulative/day) (n) } \\
<1 \text { pack-year } \\
1-18 \text { pack-years } \\
18.1-45 \text { pack-years } \\
>45 \text { pack-years }\end{array}$ & $\begin{array}{c}(374) \\
256(68.4 \%) \\
53(14.2 \%) \\
46(12.3 \%) \\
19(5.1 \%)\end{array}$ & $\begin{array}{c}(104) \\
17(16.3 \%) \\
5(4.8 \%) \\
22(21.2 \%) \\
60(57.7 \%)\end{array}$ & $<0.001$ & $\begin{array}{c}1.00 \\
1.42 \\
7.20 \\
47.55\end{array}$ & $\begin{array}{c}{[0.50-4.02]} \\
{[3.55-14.60]} \\
{[23.33-96.94]}\end{array}$ \\
\hline $\begin{array}{c}\text { Current waterpipe (cumulative/week) (n) } \\
<0.1 \text { waterpipe-year } \\
0.1-19.9 \text { waterpipe-years } \\
>=20 \text { waterpipe-years }\end{array}$ & $\begin{array}{c}(331) \\
251(75.8 \%) \\
50(15.1 \%) \\
30(9.1 \%)\end{array}$ & $\begin{array}{c}(27) \\
10(37.0 \%) \\
1(3.7 \%) \\
16(59.3 \%)\end{array}$ & $<0.001$ & $\begin{array}{c}1.00 \\
0.50 \\
13.39\end{array}$ & $\begin{array}{c}{[0.06-4.01]} \\
{[5.57-32.15]}\end{array}$ \\
\hline $\begin{array}{c}\text { Previous waterpipe frequency }(\mathrm{n}) \\
<0.1 \text { waterpipe/week } \\
0.1-3 \text { waterpipe/week } \\
>3 \text { waterpipe/week }\end{array}$ & $\begin{array}{c}(273) \\
247(89.4 \%) \\
14(5.1 \%) \\
15(5.5 \%)\end{array}$ & $\begin{array}{c}(38) \\
10(26.3 \%) \\
8(21.1 \%) \\
20(52.6 \%)\end{array}$ & $<0.001$ & $\begin{array}{c}1.00 \\
14.11 \\
32.93\end{array}$ & $\begin{array}{c}{[4.82-41.33]} \\
{[13.11-82.71]}\end{array}$ \\
\hline $\begin{array}{c}\text { Previous waterpipe duration }(\mathrm{n}) \\
<0.1 \text { year } \\
0.1-9.9 \text { years } \\
10 \text { years or more }\end{array}$ & $\begin{array}{c}(273) \\
249(90.2 \%) \\
16(5.8 \%) \\
11(4.0 \%)\end{array}$ & $\begin{array}{c}(38) \\
10(26.3 \%) \\
7(18.4 \%) \\
21(55.3 \%)\end{array}$ & $<0.001$ & $\begin{array}{c}1.00 \\
10.89 \\
47.54\end{array}$ & $\begin{array}{c}{[3.67-32.41]} \\
{[18.11-124.81]}\end{array}$ \\
\hline $\begin{array}{c}\text { Current waterpipe frequency (n) } \\
<0.5 \text { waterpipe/week } \\
0.5-2 \text { waterpipe/week } \\
2.1-7 \text { waterpipe/week } \\
>7 \text { waterpipe/week }\end{array}$ & $\begin{array}{c}(334) \\
246(73.7 \%) \\
34(10.2 \%) \\
52(15.6 \%) \\
2(0.6 \%)\end{array}$ & $\begin{array}{c}(27) \\
10(37.0 \%) \\
1(3.7 \%) \\
14(51.9 \%) \\
2(7.4 \%)\end{array}$ & 0.001 & $\begin{array}{c}1.00 \\
0.72 \\
6.62 \\
24.60\end{array}$ & $\begin{array}{c}{[0.09-5.83]} \\
{[2.79-15.73]} \\
{[3.14-192.90]}\end{array}$ \\
\hline $\begin{array}{c}\text { Current waterpipe duration }(\mathrm{n}) \\
<0.1 \text { year } \\
0.1-5 \text { years } \\
5.1-10 \text { years } \\
>10 \text { years }\end{array}$ & $\begin{array}{c}(334) \\
254(76.0 \%) \\
39(11.7 \%) \\
34(10.2) \% \\
7(2.1 \%)\end{array}$ & $\begin{array}{c}(27) \\
10(37.0 \%) \\
1(3.7 \%) \\
7(25.9 \%) \\
9(33.3 \%)\end{array}$ & $<0.001$ & $\begin{array}{c}1.00 \\
0.65 \\
5.23 \\
32.66\end{array}$ & $\begin{array}{c}{[0.08-5.23]} \\
{[1.87-14.65]} \\
{[10.11-105.49]}\end{array}$ \\
\hline
\end{tabular}

smokers. This could reflect a long lasting effect of smoking even after cessation. Yet, it could also be due to the fact that COPD cases stopped smoking more than controls [19]. It is noteworthy that in previous waterpipe smokers, the risk of having COPD is high $(\mathrm{OR}=11.67)$ although still inferior to that of previous cigarette smokers $(\mathrm{OR}=28.99)$. It is also remarkable that this risk increases in previous mixed waterpipe and cigarette smokers $(\mathrm{OR}=44.10)$, which suggest a synergistic interaction between cigarette and previous waterpipe smoking.
However, we could not find a statistically significant interaction in stratified or multivariate analysis. Although a synergistic quantitative interaction between cigarette and waterpipe smoking is possible, the sample size may have precluded confirmation of such issue in the cigarette subgroup in both analyses. Mixed smokers could be heavier smokers of cigarettes with higher risk of COPD than exclusive cigarette smokers. They could be using waterpipe only to titrate their nicotine serum levels, thus not enough to demonstrate a toxic effect; the mean cumulative dose of 


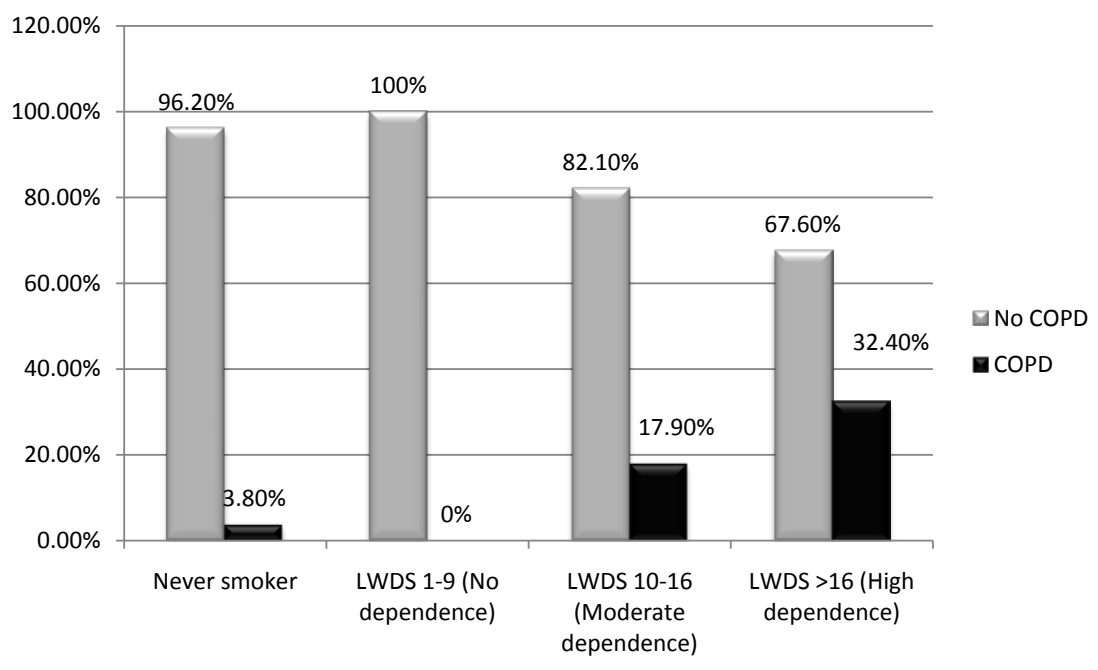

Fig. (2). Waterpipe dependence dose effect relationship. Lebanese Waterpipe Dependence Scale (LWDS) shows a positive dose-effect relationship of current waterpipe dependence with Chronic Obstructive Pulmonary Disease (COPD) ( $<0.001$ for trend).

cigarettes is higher in previous mixed smokers versus exclusive cigarette smokers. This issue remains to be studied in larger scale studies, specifically designed to study the interaction between waterpipe and cigarette smoking.

Nevertheless, the multivariate analysis results that show a positive and strong association between waterpipe smoking and COPD in never cigarette smokers, and between cumulative smoking $>20$ waterpipe-years and COPD, are in favor of waterpipe smoking toxicity leading to COPD. Eissenberg and Shihadeh [20] found that expired-air carbon monoxide, blood carboxyhemoglobin and smoke exposure were greater with waterpipe than with cigarette smoking. A recent meta-analysis concluded that waterpipe smoking is likely to be a cause of COPD [21].

Moreover and interestingly, our study is the first that shows a positive relation between waterpipe dependence and COPD, more potent than the relation between waterpipe smoking and COPD. Although comparable results were never demonstrated in the literature, our results are analogous to those found by other researchers for cigarette smoking, where tobacco dependence increases the risk of COPD [22, 23].

Situations such as ever living close to a busy road and lower education appear in our study, in certain circumstances, as risk factors for COPD. The findings of Swiss cohort studies provide strong evidence that living near busy streets leads to adverse respiratory health effects without specifying COPD itself [24]. Schikowski et al. showed [25] that living near a major road might increase the risk of developing COPD and can have a detrimental effect on lung function especially in women. As for education, similar to our results, Krzyzanowski et al. [26] found a faster rate of FEV1 decline in less educated than in more educated men; the odds ratio of obstructive lung disease in primary educated versus university educated subjects was 2.9 and the corresponding odds ratio for spirometric airflow limitation was 5.2 in a Norwegian study after adjustment for occupational and smoking exposure; [27] Tabak et al. [28] investigated the longitudinal association between baseline educational level and the rate of FEV1 decline and found that less educated women have a faster decline of FEV1 than the more educated one. Moreover, as found in other countries [29-34], we noted in our study that indoor pollution (heating home not electrically) and passive smoking are associated with a higher risk of COPD. It is therefore probable, that these factors (living close to a busy road, lower education, heating home by fuel, passive smoking) may be considered as interacting with smoking to induce a synergistic effect on development of this disease.

We noticed several drawbacks in our study. The low overall rate of waterpipe smoking in this relatively older population led to a decrease in the power of the study in several types of analyses, particularly multivariate ones. Moreover, the analysis of water-pipe smoking related to the degree of dependence and possible relationship to COPD is based on a relatively small number of waterpipe smokers in the case- and control groups; this may widen confidence intervals and decrease the robustness of our results.

A selection bias might exist since controls and cases were chosen within the same hospitals; differences in hospitals and physicians' reputation may affect this selection. Unhealthy controls (39\% of the control group) had mixed non-respiratory diagnosis and are probably non-comparable to the general population; their presence in the control group may lead to the underestimation of the associations we found. In addition, cases and controls may have geographical comparability or belonged sometimes to the same family: all this could induce an underestimation of the expected associations. On the other hand, it was not possible to get detailed information about non responders; however, answer refusals due to "lack of time" or "no reason" are expected to be both because of non-motivation or illiteracy, but not because of exposure status: all other factors being equivalent, exposed and unexposed people would have the same probability of responding. Persons with lower education level have generally lower probability of responding, and they also have higher odds of waterpipe and cigarette smoking. This may introduce a selection bias of more educated persons, but we do not expect this bias to be differential. Pulmonologists recruiting subjects were also unaware of their exposure status, especially when considering different types of 
Table 4. Final Model Results from Stepwise Multivariate Analyses for the Association Between WP and COPD

\begin{tabular}{|c|c|c|c|}
\hline Population & Major Independent Variable \& Covariates & ORa $[95 \% \mathrm{CI}]$ & p-Value \\
\hline All individuals & $\begin{array}{l}\text { Ever smoking more than } 20 \text { WP-years } \\
\text { Older age } \\
\text { Ever cigarette smoking } \\
\text { Lower education } \\
\text { Ever living close to a busy road } \\
\text { Heating home but hot air } \\
\text { Heating home not electrically }\end{array}$ & $\begin{array}{l}\mathbf{2 . 4 3}[\mathbf{1 . 1 8}-4.97] \\
1.94[1.68-2.25] \\
18.47[9.61-35.49] \\
1.46[1.15-1.84] \\
1.72[1.07-2.77] \\
2.51[1.17-5.36] \\
1.71[1.06-2.75]\end{array}$ & $\begin{array}{l}\mathbf{0 . 0 1 5} \\
<0.001 \\
<0.001 \\
0.001 \\
0.026 \\
0.018 \\
0.027\end{array}$ \\
\hline $\begin{array}{c}\text { Cigarette smokers } \\
\text { subgroup }\end{array}$ & $\begin{array}{l}\text { Ever smoking more than } 20 \text { WP-years } \\
\text { Older age } \\
\text { Lower education } \\
\text { Ever living close to a local power plant } \\
\text { Heating home but hot air } \\
\text { Having smokers inside the house }\end{array}$ & $\begin{array}{l}\mathbf{1 . 7 8}[\mathbf{0 . 7 9 - 4 . 0 3}] \\
2.14[1.81-2.54] \\
1.28[0.99-1.66] \\
1.89[1.07-3.34] \\
2.54[1.09-5.94] \\
1.65[0.96-2.82]\end{array}$ & $\begin{array}{l}\mathbf{0 . 1 6 4} \\
<0.001 \\
0.061 \\
0.028 \\
0.031 \\
0.071\end{array}$ \\
\hline $\begin{array}{c}\text { Never smokers of } \\
\text { cigarettes subgroup }\end{array}$ & $\begin{array}{l}\text { Ever smoking more than } 20 \text { WP-years } \\
\text { Older age } \\
\text { Male gender } \\
\text { Lower education } \\
\text { Ever living close to a busy road } \\
\text { Heating home not electrically }\end{array}$ & $\begin{array}{l}\mathbf{1 1 . 6 5}[\mathbf{1 . 7 6 - 7 7 . 0 8}] \\
1.44[0.94-2.20] \\
7.69[1.26-47.62] \\
6.06[2.34-15.63] \\
15.15[2.43-94.53] \\
6.67[1.14-40.00]\end{array}$ & $\begin{array}{l}\mathbf{0 . 0 1 1} \\
0.093 \\
0.027 \\
<0.001 \\
0.004 \\
0.036\end{array}$ \\
\hline $\begin{array}{c}\text { All waterpipe smokers } \\
\text { subgroup }\end{array}$ & $\begin{array}{l}\text { Ever smoking more than } 20 \text { WP-years } \\
\text { Older age } \\
\text { Ever smoking cigarettes } \\
\text { Lower education } \\
\text { Ever living close to a busy road } \\
\text { Heating home not electrically } \\
\text { Having smokers inside the house }\end{array}$ & $\begin{array}{l}\mathbf{3 . 9 1}[\mathbf{1 . 2 5}-\mathbf{1 2 . 1 9}] \\
2.08[1.49-2.90] \\
21.58[5.25-88.79] \\
2.61[1.48-4.63] \\
4.94[1.68-14.60] \\
4.52[1.54-13.33] \\
3.26[0.99-10.75]\end{array}$ & $\begin{array}{l}\mathbf{0 . 0 1 9} \\
<0.001 \\
<0.001 \\
0.001 \\
0.004 \\
0.006 \\
0.052\end{array}$ \\
\hline $\begin{array}{l}\text { Current waterpipe } \\
\text { smokers subgroup }\end{array}$ & $\begin{array}{l}\text { Ever smoking more than } 20 \text { WP-years } \\
\text { Older age } \\
\text { Ever smoking cigarettes } \\
\text { Male gender } \\
\text { Lower education } \\
\text { Ever living close to a busy road } \\
\text { Heating home not electrically }\end{array}$ & $\begin{array}{l}\mathbf{1 3 . 2 4}[\mathbf{2 . 2 1}-\mathbf{7 9 . 2 0}] \\
1.75[1.22-2.52] \\
12.13[1.61-91.54] \\
6.33[1.30-31.25] \\
3.37[1.64-6.94] \\
9.88[2.26-43.23] \\
6.25[1.47-26.32]\end{array}$ & $\begin{array}{l}\mathbf{0 . 0 0 5} \\
0.003 \\
0.016 \\
0.023 \\
0.001 \\
0.002 \\
0.013\end{array}$ \\
\hline $\begin{array}{l}\text { Current waterpipe } \\
\text { smokers subgroup }\end{array}$ & $\begin{array}{l}\text { Waterpipe dependence } \\
\text { Older age } \\
\text { Ever smoking cigarettes } \\
\text { Lower education } \\
\text { Ever living close to a busy road } \\
\text { Heating home not electrically }\end{array}$ & $\begin{array}{l}\mathbf{5 . 8 8}[\mathbf{1 . 1 1}-\mathbf{3 1 . 0 5}] \\
1.96[1.36-2.84] \\
15.75[2.33-106.25] \\
3.18[1.56-6.54] \\
7.57[1.85-31.03] \\
6.80[1.69-27.78]\end{array}$ & $\begin{array}{l}\mathbf{0 . 0 3 7} \\
<0.001 \\
0.005 \\
0.002 \\
0.005 \\
0.007\end{array}$ \\
\hline
\end{tabular}

exposure (waterpipe, cigarette and mixed smoking). This may decrease selection bias, which however cannot be totally excluded. Nevertheless, we would expect this bias be of low magnitude since we obtained a high response rate $(>90 \%)$. As for the generalizability of the results, we expect it to be for all individuals who would theoretically be treated in the tertiary centers: their geographical origin is broad (from all Lebanese regions), but their socioeconomic status may be higher than that of the general population. More pronounced results would be expected in lower socioeconomic status individuals.
A classification bias is also possible since exposure was only measured by the questionnaire, without further evaluation; as in all case-control studies, this may be subject to recall and subjectivity bias. On the other hand, to minimize confounding, multiple exposures that would be suspected to cause COPD were taken into account; however, residual confounding is still possible due to unmeasured variables, particularly since baseline variables differed between comparison groups. Thus, further studies are necessary to confirm the causality relationship of the association we found between waterpipe smoking and COPD, and to extend it to lower socioeconomic status individuals. 


\section{CONCLUSION}

In conclusion, besides cigarette smoking, waterpipe smoking and dependence measured by the validated LWDS11 score, is probably not harmless. Exposed individuals seem to have an increased risk of COPD, especially if they are waterpipe dependent persons who smoked more than 20 waterpipe-years. Other types of situations, such as living close to busy roads, heating home with wood or being less educated, have to be considered risk factors for COPD and taken into consideration on a public health perspective. Further studies are needed to confirm our findings.

\section{CONFLICT OF INTEREST}

The authors confirm that this article content has no conflicts of interest.

\section{ACKNOWLEDGEMENTS}

Declared none.

\section{REFERENCES}

[1] Serota J. A pack in 30 minutes. J Pediatr Health Care 2007; 21: 209-10.

[2] Chaouachi K. The medical consequences of narguile use in the world. Rev Epidemiol Sante Publique 2007; 55: 165-70.

[3] World Health Organization. World Health Organization study group on tobacco product regulation (TobReg). Waterpipe tobacco smoking: health effects, research needs and recommended actions by regulators. Available at: www.who.org [February 2007].

[4] Chaouachi K. Tabacologie du narguilé. Rev Alcoologie 1999; 21: 88-9.

[5] Knishkowy B, Amitai Y. Water- Pipe (Narghile) smoking: an emerging health risk behavior. Pediatrics 2005; 116: e113-9

[6] Chaouachi K. A critique of the WHO TobReg's "Advisory Note" report entitled: Waterpipe tobacco smoking: health effects, research needs and recommended actions by regulators. J Negat Results BioMed 2006; 5: 17-26

[7] Tamim H, Terro A, Kassem H, et al. Tobacco use by university students, Lebanon 2001. Addiction 2003; 98(7): 933-9.

[8] Aydin A, Kiter G, Durak H, et al. Water-pipe smoking effects on pulmonary permeability using technetium-99m DTPA inhalation scintigraphy. Ann Nucl Med 2004; 18(4): 285

[9] El HakimIE, Uthman MA. Squamous cell carcinoma and keratoacanthoma of the lower lip associated with "Goza" and "Shisha" smoking. Int J Dermatol 1999; 38(2): 108-10.

[10] Al Fayez SF, Salleh M, Ardaawi M, et al. Effects of sheesha and cigarette smoking on pulmonary function of Saudi males and females. Trop Geogr Med 1988; 40: 115-23.

[11] Nuwayhid IA, Yamout B, Azar G, et al. Waterpipe (Hubble-bubble) smoking, low birth weight, and other pregnancy outcomes. Am J Epidemiol 1998; 148(4): 375-83

[12] Mohammad Y, Kakah M, Mohammad Y. Chronic respiratory effect of narguileh smoking compared with cigarette smoking in women from the East Mediterranean region. Int J Chron Obstruct Pulmon Dis 2008; 3(3): 405-14.

[13] Radwan GN, Mohamed MK, El-Setouhy M, et al. Review on waterpipe smoking. J Egypt Soc Parasitol (Egypt) 2003; 33(3 Suppl): 105171.

[14] Salameh P, Aoun Z, Waked M. Saliva cotinine and exhaled carbon monoxide in real life narghile (waterpipe) smokers: a post hoc analysis. Tob Use Insights 2009; 2: 1-10.

[15] Salameh P, Waked M, Aoun Z. Narguileh smoking: Construction and validation of the LWDS-11 dependence scale. Nicotine Tob Res 2008; 10(1): 148-59.
[16] Buist S. Global Initiative for Chronic Obstructive Lung Disease: Global strategy for the diagnosis, management and prevention of chronic obstructive pulmonary disease. 2006. Available at: www.goldcopd.org

[17] Moolchan ET, Radzius A, Epstein DH, et al. The Fagerström Test for Nicotine Dependence and the Diagnostic Interview Schedule: Do they diagnose the same smokers? Addict Behav 2002; 27: 101-13.

[18] Maziak W, Ward KD, Afifi Soweid RA, et al. Tobacco smoking using a waterpipe: a re-emerging strain in a global epidemic.Tob Control. 2004; 13(4): 327-33.

[19] Bednarek M, Gorecka D, Wielgomas J, et al. Smokers with airway obstruction are more likely to quit smoking. Thorax 2006;61: 869-73.

[20] Eissenberg T, Shihadeh A. Waterpipe tobacco and cigarette smoking direct comparison of toxicant exposure. Am J Prev Med 2009; 37(6): 518-23.

[21] Raad D, Gaddam S, Schunemann HJ, et al. Effects of water-pipe smoking on lung function a systematic review and meta-analysis. Chest 2011; 139: 764-74.

[22] Jiménez-Ruiz CA, Masa F, Miravittles M, and the IBERPOC study investigators. Smoking characteristics: differences in attitudes and dependence between healthy smokers and smokers with COPD. Chest 2001; 119: 1365-70

[23] Jiménez-Ruiz C, Miravitlles M, Sobradillo V, et al. Can cumulative tobacco consumption, FTND score, and carbon monoxide concentration in expired air be predictors of chronic obstructive pulmonary disease? Nicotine Tob Res. 2004; 6(4): 649-53.

[24] Bayer-Oglesby L, Schindler C, von Hazenkamp ME, et al. Living near main streets and respiratory symptoms in adults: the swiss cohort study on air pollution and lung diseases in adults. Am J Epidemiol 2006; 164: 1190-8.

[25] Schikowski T, Sigiri D, Ranft U, et al. Long-term air pollution exposure and living close to busy roads are associated with COPD in women. Respir Res 2005; 6: 152.

[26] Krzyzanowski M, Jedrychowski W, Wysocki M. Factors associated with the change in ventilatory function and the development of chronic obstructive pulmonary disease in a 13-year follow-up of the Cracow study: risk of chronic obstructive pulmonary disease. Am Rev Respir Dis 1986; 134: 1011-9.

[27] Bakke PS, Hanoa R, Gulsvik A. Educational level and obstructive lung disease given smoking habits and occupational airborne exposure: a Norwegian community study. Am J Epidemiol 1995; 141: 1080-8.

[28] Tabak C, Spijkerman AMW, Verschuren WMM, et al. Does educational level influence lung function decline (Doetinchem Cohort Study)? Eur Respir J 2009; 34: 940-7.

[29] Zhou Y, Wang C, Yao W, et al. COPD in Chinese nonsmokers. Eur Respir J 2009; 33: 509-18.

[30] Eisner MD, Anthonisen N, Coultas D, et al. on behalf of the Environmental and occupational health assembly committee on nonsmoking COPD. An official American Thoracic Society public policy statement: novel risk factors and the global burden of chronic obstructive pulmonary disease. Am J Respir Crit Care Med 2010; 182(5): 693-718.

[31] Jindal SK, Aggarwal AN, Chaudhry K, et al; Asthma Epidemiology Study Group. A multicentric study on epidemiology of chronic obstructive pulmonary disease and its relationship with tobacco smoking and environmental tobacco smoke exposure. Indian J Chest Dis Allied Sci 2006; 48(1): 23-9.

[32] Salvi SS, Barnes PJ. Chronic obstructive pulmonary disease in nonsmokers. Lancet 2009; 374(9691): 733-43.

[33] Eisner MD. Secondhand smoke and obstructive lung disease: a causal effect? Am J Respir Crit Care Med 2009; 179(11): 973-4.

[34] Yin P, Jiang CQ, Cheng KK, et al. Passive smoking exposure and risk of COPD among adults in China: the Guangzhou Biobank Cohort Study. Lancet 2007; 370: 751-7. 